\title{
AVALIAÇÃO DO DESENVOLVIMENTO DE MARACUJÁ-DOCE (Passiflora alata Dryander) PROPAGADO POR ESTAQUIA E POR SEMENTE EM CONDIÇÕES DE POMAR COMERCIAL ${ }^{1}$
}

\author{
GIVANILDORONCATTO², GERALDOCOSTANOGUEIRAFILHO 3 , CARLOS RUGGIERO ${ }^{4}$, \\ JOÃO CARLOS DE OLIVEIRA ${ }^{4}$,ANTÔNIO BALDO GERALDO MARTINS ${ }^{4}$
}

RESUMO - O trabalho foi realizado na Área de Propagação de Fruteiras do Departamento de Produção Vegetal da Faculdade de Ciências Agrárias e Veterinárias, Universidade Estadual Paulista (FCAV/UNESP), Jaboticabal-SP, e em área de produtor, no município de Araguari-MG, com o objetivo de verificar o potencial de crescimento vegetativo (diâmetro do caule, altura de plantas e número de folhas) de plantas de maracujá-doce (Passiflora alata Dryander), obtidas por estaquia e por semente, comparando o desenvolvimento inicial de plantas no campo. O experimento foi conduzido no período de janeiro de 2002 a fevereiro de 2003 . A formação de mudas por semente foi realizada em casa de vegetação e, por estaca, em câmara de nebulização intermitente, sob condições de telado. As estacas e sementes foram coletadas de plantas adultas, oriundas do Banco de Germoplasma Ativo (BAG) do Departamento de Produção Vegetal da FCAV/UNESP. Para as estacas, utilizou-se a parte intermediária de ramos em estádio de crescimento vegetativo. As sementes, para a obtenção das plântulas, foram semeadas em bandejas plásticas. Efetuou-se o transplantio de estacas e de plântulas, para sacos de polietileno, mantido sob telado e irrigado diariamente por aspersão, para aclimatação e plantio no campo, após 60 dias. O diâmetro do caule, a altura e o número de folhas de plantas obtidas por estaca foram maiores do que nas obtidas por semente, em Jaboticabal-SP. Já em Araguari-MG, o diâmetro do caule foi maior naquelas oriundas de semente, enquanto a altura e o número de folhas foram maiores nas plantas propagadas por estacas.

Termos para Indexação: porta-enxerto, crescimento, diâmetro, altura, número de folhas.

\section{EVALUATION AND DEVELOPMENT OF PASSION FRUIT (Passiflora alata DRYANDER) PROPAGATED BY CUTTING AND SEED IN CONDITIONS OF COMMERCIAL ORCHARD}

\begin{abstract}
The present work was conducted in a fruit tree propagation area of the Plant Production Department of the Faculdade de Ciências Agrárias e Veterinárias, Universidade Estadual Paulista (FCAV/UNESP) in Jaboticabal, SP, and also in a commercial orchard in Araguari, MG, with the objective to verify the potential of vegetative growth (stem diameter, height of plants and leaf number) of plants of passion fruit (Passiflora alata Dryander), gotten by cutting and seed, comparing the initial development of plants in the field. This experiment was carried out from January 2002 to February 2003. The experiment using seeds was conducted at a shadow house, and the one that used cuttings in an intermitent mist. The cuttings and seeds were collected from adult plants which came from Passifloraceae Active Germoplasm Bank (BAG) of the Plant Production Department of FCAV/UNESP. For the cuttings, it was used the intermediate part of the branches in stadium of vegetative growth. The seeds, in order to obtain the seedlings, had been sown in plastic trays. Cuttings and seedlings were transplanted to plastic bags with substrate in shadow house and with daily irrigation. They were acclimatized and planted on field, after 60 days. On field, the stem diameter, plant height and number of leaves were better for cuttings than for seedlings in Jaboticabal, SP. In Araguari, MG, stem diameter was larger in the seedlings, while plant heigths and number of leaves were larger on cuttings.
\end{abstract}

Index Terms: rootstocks, growth, diameter, plant height and number of leaves.

\section{INTRODUÇÃO}

A cultura do maracujazeiro (Passiflora spp.) intensificouse no País na década de 70, colocando-se entre as principais frutíferas cultivadas. Atualmente, o Brasil é o maior produtor mundial, com área de aproximadamente 36 mil hectares e produção de aproximadamente meio milhão de toneladas, destacando-se a Bahia como principal Estado produtor, representando 28\% da produção nacional. Em seguida, o Estado de São Paulo, produzindo 41 mil toneladas em 2,3 mil hectares (IBGE, 2007).
O maracujazeiro é propagado por sementes, mas a autoincompatibilidade dificulta a transmissão das características agronômicas desejáveis, para as progênies, na formação de pomares de qualidade superior, com produtividade, precocidade, longevidade, resistência a pragas e doenças, seca, nematóides, qualidade de frutos, alto teor de sólidos solúveis totais, acidez, rendimento de suco e tamanho de frutos (São José, 1991).

A propagação vegetativa permite a clonagem de indivíduos, transmitindo às plantas características agronômicas desejáveis na formação de pomares. Dessa forma, a formação de matrizes selecionadas, juntamente com a produção de mudas

1(Trabalho 239-07). Recebido em: 04-10-2007. Aceito para publicação em: 10-04-2008.

${ }^{2}$ Pesquisador da Embrapa Acre. Rodovia BR 364 km 14, Zona Rural, Cep 69901180 Rio Branco-AC. E-mail: givanildo@cpafac.embrapa.br ${ }^{3}$ In memorian

${ }^{4}$ Professor Titular da Unesp/FCAV. Via de acesso Paulo Donato Castellane, s/n Cep 14884-900 Jaboticabal-SP. 
assexuadamente, evita a segregação do material que ocorre na propagação de sementes, fazendo com que não ocorra perda das características genéticas, adquiridas no processo de melhoramento (São José, 1991).

Por isso, é importante a criação de protocolos para produção de mudas por estaquia, processo de reprodução já utilizado na África do Sul, mas ainda não recomendado no Brasil para áreas comerciais. Os resultados de pesquisa sobre formação de mudas por estaquia são restritos, sendo que alguns autores já tiveram êxito na fase de enraizamento de estacas no maracujáamarelo (P. edulis Sims f. flavicarpa Degener) e noutras espécies menos conhecidas. Oliveira et al. (2002) obtiveram 75\% de enraizamento no maracujá-amarelo, e Salomão et al. (2002), 96\%. Estes últimos, quando trabalharam com maracujá-doce ( $P$. alata Dryander), obtiveram 94\% de enraizamento, e Lima et al. (2000) obtiveram $97 \%$.

No entanto, estes mesmos autores mencionam a falta de prosseguimento nos estudos das etapas posteriores ao enraizamento do maracujazeiro, que é a formação de pomares por estaquia. Pouco se sabe sobre o comportamento no campo dos indivíduos formados por este método, em termos de produtividade, qualidade de frutos e suscetibilidade a doenças.

Neste sentido, Menezes (1990) e Menezes et al. (1994) observaram o crescimento e a produção do maracujá-amarelo enxertados sobre o maracujá-doce, mas não obtiveram diferença em relação ao maracujá-amarelo de semente. Já Cereda \& Papa (1989) observaram que esta espécie, quando propagada por estaca, desenvolve-se melhor do que por sementes. Da mesma forma, Melo (1999) observou que o P. nitida H.B.K. por estaquia teve um desenvolvimento inicial maior que por semente, bem como precocidade na produção.

O objetivo do trabalho foi avaliar o crescimento vegetativo (diâmetro do caule, altura de plantas e número de folhas) de plantas de maracujá-doce, obtidas por estaquia e por semente, comparando o desenvolvimento inicial das plantas em condições de pomar em Jaboticabal-SP, e em Araguari-MG.

\section{MATERIAL E MÉTODOS}

A área experimental pertence ao Departamento de Produção Vegetal da Faculdade de Ciências Agrárias e Veterinárias, Universidade Estadual Paulista (FCAV/UNESP), Câmpus de Jaboticabal, cujas coordenadas geográficas são latitude $21^{\circ} 17^{\prime} 05^{\prime \prime S}$ e longitude $48^{\circ} 17^{\prime} 09^{\prime \prime} \mathrm{W}$, altitude de aproximadamente $590 \mathrm{~m}$. O clima da região, segundo classificação de Koppen é do tipo Cwa, subtropical, relativamente seco no inverno, com chuvas no verão, apresentando temperatura média anual de $22^{\circ} \mathrm{C}$ e precipitação de $1.552 \mathrm{~mm}$.

As mudas por estacas foram obtidas em trabalho conduzido sob telado (50\% de luminosidade) equipado com sistema de nebulização intermitente, em janeiro de 2002. As matrizes da espécie $P$. alata pertencem ao Banco de Germoplasma Ativo (BAG), do Departamento de Produção Vegetal. As características observadas nas plantas-matrizes foram: sanidade, vigor vegetativo, produtividade e qualidade de frutos. As estacas foram retiradas da porção mediana de ramos em crescimento vegetativo e enraizadas sob condições de nebulização intermitente.

O transplante das estacas enraizadas foi em março de 2002 , retirando-as das bandejas com vermiculita para sacos pretos de polietileno perfurados, com dimensões de $10 \times 25 \times 0,02 \mathrm{~cm}$, contendo como substrato uma mistura de solo, esterco e areia, na proporção $3: 1: 1$. Em seguida, as mudas foram levadas para ambiente de ripado, coberto por sombrite (50\% de luminosidade), onde passaram a receber irrigação por aspersão diária, permitindo a aclimatação, ficando sob estas condições por dois meses.

Para a obtenção de mudas por semente, foram utilizadas sementes de plantas-matrizes do BAG do Departamento de Produção Vegetal da FCAV/UNESP-Jaboticabal-SP. Após a colheita e processamento, em julho de 2001, as sementes foram acondicionadas em sacos de papel e armazenadas em refrigerador (cerca de $10^{\circ} \mathrm{C}$ ). A semeadura foi feita em casa de vegetação, em janeiro de 2002, utilizando-se de bandejas plásticas com substrato comercial Plantmax, onde foram semeadas 100 sementes previamente preparadas com pré-embebição por 24 horas e distribuídas por toda a superfície da bandeja. A emergência ocorreu 30 dias após a semeadura e, quando as plântulas atingiram $4 \mathrm{a} 5 \mathrm{~cm}$ de altura, foram transplantadas individualmente para sacos de polietileno, utilizando a mesma mistura das mudas por estacas.

O plantio foi feito em duas áreas: na Área de Fruteiras do Departamento de Produção Vegetal (FCAV/UNESP) em Jaboticabal-SP, e em produtor rural em Araguari-MG. Antes do plantio definitivo, foi feita quarentena de mudas, permanecendo 40 dias em casa de vegetação com cortina de náilon branca antiafídeo, modelo utilizado para borbulheiras de citros, para análise visual de viroses. As mudas foram transplantadas quando atingiram $25-35 \mathrm{~cm}$ de altura, quatro a seis pares de folhas e na ocasião da emissão das primeiras gavinhas. As covas foram previamente preparadas, com dimensões $40 \times 40 \times 40 \mathrm{~cm}$, adubadas com resíduo de biodigestor como fonte de matéria orgânica, NPK e micronutrientes, de acordo com as recomendações de Piza Junior et al. (1997).

No momento do plantio, a muda foi colocada acima do nível do solo, envolvido por uma bacia de captação de água em "coroamento", capaz de acomodar a água de irrigação. No período de seca, a freqüência de irrigação foi de duas vezes por semana, utilizando tanque d'água acoplado ao trator.

O sistema de condução, para as duas áreas de plantio, foi o de espaldeira, com um fio de arame a $2 \mathrm{~m}$ do solo, em linhas de 30 metros, permitindo o tutoramento das plantas, guiadas por cordão fixado no solo por uma das extremidades e, no fio da espaldeira, pela outra. Desta forma, as plantas foram conduzidas em haste única, executando-se a poda de formação, através do desbrote das brotações laterais, com desponte na altura do fio da espaldeira. Foram conduzidos 2 ramos laterais secundários, em sentido oposto, onde foram emitidos os ramos terciários e quaternários em cortina, crescimento livre, completando a formação da planta. A realização dos tratos culturais, tais como tutoramento, manejo da área com capina na linha, roçada e aplicação de herbicida total na entrelinha, adubação de manutenção e controle fitossanitário foram feitos de acordo com 
o recomendado para o maracujá-amarelo por Ruggiero (1996). As avaliações realizadas no período compreendido entre maio de 2002 e fevereiro de 2003 foram: Altura, medidas mensais da altura das plantas, com régua graduada, até a ocasião do desponte, quando as plantas atingiram a espaldeira; Diâmetro, medido mensalmente, com paquímetro digital, a $5 \mathrm{~cm}$ acima da região do colo da planta; Número de folhas, contagem do número de folhas foi feita na ocasião da avaliação da altura das plantas, como medida de vigor.

O delineamento experimental utilizado foi o de blocos ao acaso, com 6 repetições e 4 plantas por parcela, em esquema fatorial $2 \times 2$, composto de 2 fatores: método de propagação (semente e estaca) e local (Araguari e Jaboticabal). Os dados foram submetidos à análise de variância, utilizando-se, para teste F, do nível de 5\% e 1\% de probabilidade, executados no Sistema para Análises Estatísticas (ESTAT) do Pólo Computacional do Departamento de Ciências Exatas da FCAV/UNESP. As médias foram comparadas entre si, pelo teste de Tukey, a $5 \%$ e $1 \%$ de probabilidade. Os dados não foram transformados.

\section{RESULTADOS E DISCUSSÃO}

Observa-se que o diâmetro do caule, a altura de plantas e o número de folhas tiveram comportamento distinto (Tabelas $1 \mathrm{e}$ 2) quando oriundos da estaquia e/ou de sementes de maracujádoce, em Jaboticabal-SP e Araguari-MG. Num primeiro momento, não houve interação entre os fatores no início do crescimento, para o diâmetro do caule e altura de planta; entretanto, em relação ao número de folhas, houve interação apenas em maio, considerando-se que o período avaliado foi até outubro.

$\mathrm{O}$ diâmetro do caule foi maior em plantas originadas de sementes em relação às produzidas por estaca em Araguari (Figura 1), enquanto em Jaboticabal as oriundas de estaca foram maiores, a partir de julho. Esse comportamento não foi observado em relação à altura de planta e número de folhas, quando as provenientes de estacas foram maiores, se comparadas com as provenientes de sementes, tanto em Araguari quanto em Jaboticabal, em agosto e setembro.

Em relação à estaquia em $P$. alata a campo, não foram encontrados trabalhos sobre o desenvolvimento inicial, tornando-se necessário buscar informações em estudos feitos noutras espécies de maracujazeiro.

Neste sentido, a superioridade nos parâmetros de crescimento, para as plantas obtidas por estaquia, em Jaboticabal, foram semelhantes ao observado por Melo (1999) na espécie $P$. nitida, que observou maior altura nas plantas obtidas por estaquia, representando melhor desenvolvimento neste período inicial. Cereda \& Papa (1989) também observaram melhor crescimento das plantas obtidas por estaca, na formação de pomares do maracujá-amarelo. Já Almeida et. al. (1991) e São José et al. (1993) não observaram diferença no desenvolvimento das plantas obtidas por estaquia, em relação às por semente, nesta espécie.

Para a P. alata, Menezes (1990) e Menezes et al. (1994) observaram o desenvolvimento inicial em plantas enxertadas sob o maracujá-amarelo, sendo que o diâmetro do caule não foi diferente quando comparado ao maracujá-amarelo. Salientam os autores, que pode ter ocorrido influência da copa sobre o portaenxerto, no desenvolvimento de plantas em $P$. alata.

O crescimento maior do diâmetro do caule das plantas por semente, observado em Araguari, a partir de julho, contraria os estudos mencionados anteriormente, que mostraram pelo menos o mesmo desenvolvimento inicial no estádio vegetativo de plantas, ou até melhor quando por estaca, em maracujazeiros, além do que as demais variáveis (altura de planta e número de folhas) foram maiores naquelas obtidas por estaca.

Os resultados obtidos e pesquisados mostram escassez de informações sobre técnicas de estaquia e plantas no campo, em termos de crescimento vegetativo, produção e qualidade tecnológica dos frutos, demonstrando a necessidade de dar continuidade aos estudos.

TABELA 1 - Altura de plantas (cm) oriundas de semente e de estaquia de maracujá-doce, no período de maio a setembro de 2002 em Jaboticabal-SP e Araguari-MG.

\begin{tabular}{|c|c|c|c|c|c|c|}
\hline & \multicolumn{6}{|c|}{ Período } \\
\hline & \multicolumn{2}{|c|}{ Maio } & \multicolumn{2}{|c|}{ Junho } & \multicolumn{2}{|c|}{ Julho } \\
\hline Método & \multicolumn{2}{|c|}{ Araguari/Jaboticabal $^{1 /}$} & \multicolumn{2}{|c|}{ Araguari/Jaboticabal } & \multicolumn{2}{|c|}{ Araguari/Jaboticabal } \\
\hline Semente & \multicolumn{2}{|c|}{$22,09 \mathrm{~B}$} & \multicolumn{2}{|c|}{$34,81 \mathrm{~B}$} & \multicolumn{2}{|c|}{$39,29 \mathrm{~B}$} \\
\hline Estaca & \multicolumn{2}{|c|}{$80,42 \mathrm{~A}$} & \multicolumn{2}{|c|}{$92,29 \mathrm{~A}$} & \multicolumn{2}{|c|}{$111,17 \mathrm{~A}$} \\
\hline $\mathrm{F}$ & \multicolumn{2}{|c|}{$16,11 * *$} & \multicolumn{2}{|c|}{$17,86 * *$} & \multicolumn{2}{|c|}{$36,38 * *$} \\
\hline D.M.S. & \multicolumn{2}{|c|}{30,92} & \multicolumn{2}{|c|}{28,95} & \multicolumn{2}{|c|}{25,36} \\
\hline C.V. & \multicolumn{2}{|c|}{69,44} & \multicolumn{2}{|c|}{52,42} & \multicolumn{2}{|c|}{38,80} \\
\hline \multicolumn{7}{|c|}{ Período } \\
\hline & \multicolumn{2}{|c|}{ Agosto } & \multicolumn{4}{|c|}{ Setembro } \\
\hline Método & Araguari $^{1 /}$ & Jaboticabal & $\mathbf{F}$ & Araguari $^{1 /}$ & Jaboticabal & $\mathrm{F}$ \\
\hline Semente & $97,52 \mathrm{Ba}$ & $36,33 \mathrm{Bb}$ & $19,41 * *$ & $141,88 \mathrm{Aa}$ & $52,92 \mathrm{Bb}$ & $30,30 * *$ \\
\hline Estaca & $129,67 \mathrm{Aa}$ & $147,46 \mathrm{Aa}$ & $1,64^{\mathrm{NS}}$ & $156,17 \mathrm{Aa}$ & $159,17 \mathrm{Aa}$ & $0,35^{\mathrm{NS}}$ \\
\hline $\mathrm{F}$ & $5,36 *$ & $64,03 * *$ & & $0,78^{\mathrm{NS}}$ & $43,23 * *$ & \\
\hline D.M.S. & 29,56 & & & 34,40 & & \\
\hline C.V. $(\%)$ & 23,41 & & & 21,95 & & \\
\hline
\end{tabular}

${ }^{1 /}$ Médias seguidas pela mesma letra minúscula na horizontal, e maiúscula na vertical, não diferem entre si, pelo teste de Tukey, a 5\% de probabilidade. 
TABELA 2 - Número de folhas de plantas oriundas de semente e de estaquia de maracujá-doce, no período de maio a outubro de 2002 em Jaboticabal-SP e Araguari-MG.

\begin{tabular}{|c|c|c|c|c|c|c|}
\hline \multirow[b]{3}{*}{ Método } & \multicolumn{4}{|c|}{ Período } & & \\
\hline & \multicolumn{4}{|c|}{ Maio } & & \\
\hline & \multicolumn{2}{|c|}{ Araguari ${ }^{1 /}$} & \multicolumn{2}{|c|}{ Jaboticabal } & \multicolumn{2}{|l|}{$\mathrm{F}$} \\
\hline Semente & \multicolumn{2}{|c|}{$7,38 \mathrm{Aa}$} & \multicolumn{2}{|c|}{$6,14 \mathrm{Ba}$} & \multicolumn{2}{|c|}{$0,42^{1 \mathrm{NS}}$} \\
\hline Estaca & \multicolumn{2}{|c|}{$6,92 \mathrm{Ab}$} & \multicolumn{2}{|c|}{$14,58 \mathrm{Aa}$} & \multicolumn{2}{|c|}{$16,05 * *$} \\
\hline $\bar{F}$ & \multicolumn{2}{|c|}{$0,06^{\mathrm{NS}}$} & \multicolumn{2}{|c|}{$19,46^{* *}$} & & \\
\hline D.M.S. & \multirow{2}{*}{\multicolumn{2}{|c|}{$\begin{array}{c}4,07 \\
37,86\end{array}$}} & & & & \\
\hline C.V. $(\%)$ & 37,86 & & & & & \\
\hline & \multicolumn{4}{|c|}{ Período } & & \\
\hline & \multicolumn{2}{|c|}{ Junho } & \multicolumn{2}{|l|}{ Julho } & \multicolumn{2}{|c|}{ Agosto } \\
\hline Método & \multicolumn{2}{|c|}{ Araguari/Jaboticabal } & \multicolumn{2}{|c|}{ Araguari/Jaboticabal } & \multicolumn{2}{|c|}{ Araguari/Jaboticabal } \\
\hline Semente & \multicolumn{2}{|c|}{$9,67 \mathrm{~B}$} & \multicolumn{2}{|c|}{$10,15 \mathrm{~B}$} & \multicolumn{2}{|c|}{$13,02 \mathrm{~B}$} \\
\hline Estaca & \multicolumn{2}{|c|}{$14,15 \mathrm{~A}$} & \multicolumn{2}{|c|}{$17,10 \mathrm{~A}$} & \multicolumn{2}{|c|}{$17,79 \mathrm{~A}$} \\
\hline $\mathrm{F}$ & \multicolumn{2}{|c|}{$5,43^{*}$} & \multicolumn{2}{|c|}{$16,35^{* *}$} & \multicolumn{2}{|c|}{$7,28^{*}$} \\
\hline D.M.S. & \multicolumn{2}{|c|}{$\begin{array}{c}4,08 \\
3944\end{array}$} & \multicolumn{2}{|l|}{3,66} & \multicolumn{2}{|l|}{3,76} \\
\hline C.V. $(\%)$ & 39,44 & & 30,94 & & 28,11 & \\
\hline & & & Período & & & \\
\hline & & & & & bro & \\
\hline Método & Araguari ${ }^{1 /}$ & Jaboticabal & $\mathrm{F}$ & Araguari & Jaboticabal & $\mathrm{F}$ \\
\hline Semente/ Estaca & $19,06 \mathrm{a}$ & $13,65 b$ & $8,79^{* *}$ & $19,06 \mathrm{a}$ & $13,27 b$ & $12,35^{* *}$ \\
\hline D.M.S. & 3,89 & 3,66 & & 3,51 & & \\
\hline C.V. $(\%)$ & 27,36 & 30,94 & & 24,96 & & \\
\hline
\end{tabular}

${ }^{1 /}$ Médias seguidas pela mesma letra minúscula na horizontal, e maiúscula na vertical, não diferem entre si, pelo teste de Tukey, a $5 \%$ de probabilidade.

\section{CONCLUSÕES}

Nas condições em que foi desenvolvido o experimento, pode-se concluir que:

1-O diâmetro do caule, a altura de planta e o número de folhas de Passiflora alata, oriundas de estacas, foram maiores em Jaboticabal.

2-O diâmetro do caule das plantas de P. alata oriundas de semente foi maior em Araguari-MG. Já a altura de planta e o número de folhas foram maiores nas plantas obtidas por estaquia.

\section{REFERÊNCIAS}

ALMEIDA, L.P. de; BOARETTO, M.A.C.; SANTANA, R.G. de. Estaquia e comportamento de maracujazeiros (Passiflora edulis Sims f. flavicarpa Degener) propagados por via sexual e vegetativa. Revista Brasileira de Fruticultura, Jaboticabal, v.13, n.1, p.157-159, 1991.

CEREDA, E.; PAPA, R.C.R. Enraizamento de estacas das espécies de maracujazeiro P. alata Dryand e Passiflora edulis Sims f. flavicarpa Degener sob nebulização. In: CONGRESSO BRASILEIRO DE FRUTICULTURA, 10., 1989, Fortaleza. Anais... p.375-378.

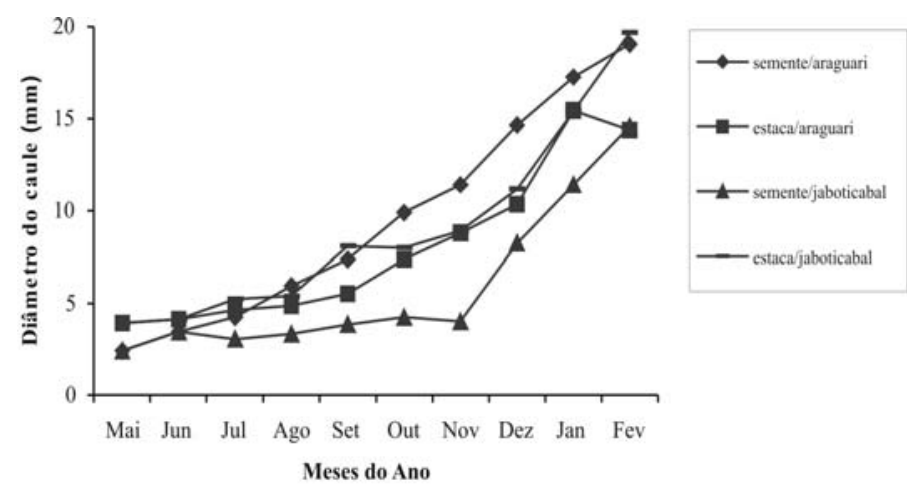

FIGURA 1- Diâmetro do caule (mm) de plantas de $P$. alata por semente e por estaca. Jaboticabal-SP e AraguariMG, 2003.
IBGE - Instituto Brasileiro de Geografia e Estatística. Produção Agrícola Municipal. Maracujá. Brasília: Ministério do Planejamento, Orçamento e Gestão, 2007. Disponível em: <http:/ /www.sidra.ibge.gov.br/bda/tabela/protabl.asp? $\mathrm{z}=\mathrm{t} \& \mathrm{o}=10 \& \mathrm{i}=\mathrm{P}>$. Acesso em: 19 ago. 2007.

LIMA, E. de S.; CORRÊA, L. de S.; BOLIANI, A.C. Épocas de plantio, tipos de estacas e concentrações de ácido indolbutírico, no enraizamento de estacas de maracujazeiro-doce (Passiflora alata Dryander). In: CONGRESSO BRASILEIRO DE FRUTICULTURA, 16., 2000, Fortaleza. Anais... p.486.

MELO, A.L. de. Métodos de quebra de dormência, e de armazenamento de sementes, $e$ aspectos de obtenção de mudas de maracujá-suspiro (Passiflora nitida H.B.K.). 1999. 95 f. Tese (Doutorado em Agronomia, Área de Produção Vegetal) Faculdade de Ciências Agrárias e Veterinárias, Universidade Estadual Paulista, Jaboticabal, 1999.

MENEZES, J.M.T. Seleção de porta-enxertos tolerantes à morte prematura de plantas para $P$. edulis Sims f. flavicarpa Deg. e comportamento de $P$. nitida H.B.K. na região de Jaboticabal. 1990. 73 f. Dissertação (Mestrado em Melhoramento Genético Vegetal) - Faculdade de Ciências Agrárias e Veterinárias, Universidade Estadual Paulista, Jaboticabal, 1990.

MENEZES, J.M.T.; OLIVEIRA, J.C. de; RUGGIERO, C.; BANZATTO, D. A. Avaliação da taxa de pegamento de enxertos de maracujá-amarelo sobre espécies tolerantes à "morte prematura de plantas”. Científica, São Paulo, v.22, n.1, p.95-104, 1994. 
OLIVEIRA, J.A. de; JUNQUEIRA, N.T.V.; PEIXOTO, J.R.; PEREIRA A.V. Efeito dos substratos artificiais no enraizamento e no desenvolvimento de estacas de maracujazeiro-azedo (Passiflora edulis Sims f. flavicarpa Deg.). Revista Brasileira de Fruticultura, Jaboticabal, v.24, n.2, p.505-508, 2002.

PIZA JUNIOR, C. de T.; QUAGGIO, J.A.; MELETTI, L.M.M.; SILVA, J.R. da; SÃO JOSÉ, A.R.; KARATI, R. Maracujá. In: VAN RAIJ, B. Recomendações de adubação e calagem para o Estado de São Paulo. Campinas: Instituto Agronômico/Fundação IAC, 1997. p.148. (Boletim Técnico, 100)

RUGGIERO, C. (Coord.). Maracujá para exportação: aspectos técnicos. Brasília: EMBRAPA-SPI, 1996. p. 11-29.
SALOMÃO, L.C.C.; PEREIRA, W.E.; DUARTE, R.C.C.; SIQUEIRA, D.L.D. Propagação por estaquia dos maracujazeirosdoce (Passiflora alata Dryand.) e amarelo (P. edulis f. flavicarpa Deg.). Revista Brasileira de Fruticultura, Jaboticabal, v.24, n.1, p.163-167, 2002.

SÃO JOSÉ, A.R. Propagação do maracujazeiro. In: FEREIRA, F.R.; VAZ, R.L. A cultura do maracujá no Brasil. Jaboticabal: FUNEP, 1991. p.25-41.

SÃO JOSÉ, A.R.; ALMEIDA, L.P. de; SANTANA, R.G. de; SOUSA, P.J.S. de. Comportamento de maracujazeiros (P. edulis Sims f. flavicarpa Degener) propagados por via sexual e vegetativa. Revista Brasileira de Fruticultura, Jaboticabal, v.15, n.1,p.159-164, 1993. 